\title{
Platelet-Activating Factor Receptors Mediate Excitatory Postsynaptic Hippocampal Injury in Experimental Autoimmune Encephalomyelitis
}

\author{
@Matthew J. Bellizzi, ${ }^{1}{ }^{-}$Jasmine S. Geathers, ${ }^{2}{ }^{-}$Kevin C. Allan, ${ }^{2}$ and ${ }^{\oplus}$ Harris A. Gelbard ${ }^{3}$ \\ ${ }^{1}$ Center for Neural Development and Disease and Department of Neurology (Neuroimmunology Division), University of Rochester Medical Center, \\ Rochester, New York 14642, ${ }^{2}$ Center for Neural Development and Disease, University of Rochester Medical Center, Rochester, New York 14642 , and ${ }^{3}$ Center \\ for Neural Development and Disease, Departments of Neurology (Child Neurology Division), Pediatrics, and Microbiology and Immunology, University of \\ Rochester Medical Center, Rochester, New York 14642
}

Gray matter degeneration contributes to progressive disability in multiple sclerosis (MS) and can occur out of proportion to measures of white matter disease. Although white matter pathology, including demyelination and axon injury, can lead to secondary gray matter changes, we hypothesized that neurons can undergo direct excitatory injury within the gray matter independent of these. We tested this using a model of experimental autoimmune encephalomyelitis (EAE) with hippocampal degeneration in C57BL/6 mice, in which immunofluorescent staining showed a 28\% loss of PSD95-positive excitatory postsynaptic puncta in hippocampal area CA1 compared with sham-immunized controls, despite preservation of myelin and VGLUT1-positive excitatory axon terminals. Loss of postsynaptic structures was accompanied by appearance of PSD95-positive debris that colocalized with the processes of activated microglia at $25 \mathrm{~d}$ after immunization, and clearance of debris was followed by persistently reduced synaptic density at $55 \mathrm{~d}$. In vitro, addition of activated BV2 microglial cells to hippocampal cultures increased neuronal vulnerability to excitotoxic dendritic damage following a burst of synaptic activity in a manner dependent on platelet-activating factor receptor (PAFR) signaling. In vivo treatment with PAFR antagonist BN52021 prevented PSD95-positive synapse loss in hippocampi of mice with EAE but did not affect development of EAE or local microglial activation. These results demonstrate that postsynaptic structures can be a primary target of injury within the gray matter in autoimmune neuroinflammatory disease, and suggest that this may occur via PAFR-mediated modulation of activity-dependent synaptic physiology downstream of microglial activation.

Key words: excitotoxicity; microglia; multiple sclerosis; neurodegeneration; neuroprotection; platelet-activating factor

\section{Significance Statement}

Unraveling gray matter degeneration is critical for developing treatments for progressive disability and cognitive impairment in multiple sclerosis (MS). In a mouse model of MS, we show that neurons can undergo injury at their synaptic connections within the gray matter, independent of the white matter pathology, demyelination, and axon injury that have been the focus of most current and emerging treatments. Damage to excitatory synapses in the hippocampus occurs in association with activated microglia, which can promote excitotoxic injury via activation of receptors for platelet-activating factor, a proinflammatory signaling molecule elevated in the brain in MS. Platelet-activating factor receptor blockade protected synapses in the mouse model, identifying a potential target for neuroprotective treatments in MS.

\section{Introduction}

Gray matter degeneration contributes to chronic disability and cognitive impairment in patients with multiple sclerosis (MS), and progresses despite current treatments (Amato et al., 2004; Fisniku et al., 2008; Rudick et al., 2009). MRI and pathology studies show evidence of widespread neuronal injury in the gray analyzed data; M.J.B. wrote the paper.

This work was supported by National Multiple Sclerosis Society-American Brain Foundation Clinician Scientist Development Award FAN1758-A1 to M.J.B. and National Institutes of Health Grant R01 MH56838 to H.A.G.
The authors declare no competing financial interests.

Correspondence should be addressed to Dr. Matthew J. Bellizzi, Department of Neurology, Neuroimmunology Division, 601 Elmwood Avenue, Box 605, Rochester, NY 14642. E-mail: Matthew_Bellizzi@urmc.rochester.edu. DOI:10.1523/JNEUROSCI.1171-15.2016

Copyright $\odot 2016$ the authors $\quad 0270-6474 / 16 / 361336-11 \$ 15.00 / 0$ 
matter, both inside and outside of focal demyelinating lesions (Dehmeshki et al., 2003; Vrenken et al., 2006; Magliozzi et al., 2010). This has been increasingly recognized as an important target for the treatment of progressive MS, but how it occurs is unknown.

Much attention has been focused on myelin loss, which can increase metabolic demands and reduce trophic support for neurons and their synaptic connections (Dutta et al., 2011; Simons et al., 2014), and on axon injury that can trigger neuronal degeneration via anterograde, retrograde and trans-synaptic effects (Dutta and Trapp, 2011). However, imaging markers of demyelination and axon injury often correlate poorly with gray matter atrophy in MS patients (Sbardella et al., 2013), suggesting additional mechanisms of gray matter injury.

We propose that neuronal synapses are particularly vulnerable to damage in MS gray matter, where neuronal injury occurs alongside activated microglia in both myelinated and demyelinated areas (Magliozzi et al., 2010). Microglial activation has been linked to increased levels of proinflammatory cytokines, oxidative stress (Haider et al., 2011), and altered glutamate reuptake (Vercellino et al., 2007) in MS gray matter, which can all promote excitotoxic injury. Excitatory postsynaptic elements can be especially vulnerable during activity-dependent plasticity: we have previously found that platelet-activating factor (PAF), a proinflammatory molecule elevated several thousand-fold in MS CSF (Callea et al., 1999), can shift the boundary between physiologic plasticity and excitotoxic injury (Bellizzi et al., 2005) likely by modulating signals, including nitric oxide production, mitochondrial calcium influx, and caspase activation. We hypothesize that synaptic injury in MS gray matter may occur independent of demyelination or axotomy, and may be a critical target for neuroprotective treatments.

It is difficult in MS to distinguish between injury that has occurred directly at the synapse versus damage secondary to demyelination and/or axon injury, which are common and may exert long-distance effects along projection pathways (Dutta and Trapp, 2011; Simons et al., 2014). The hippocampal pathology of mice with experimental autoimmune encephalomyelitis (EAE) induced by myelin oligodendrocyte glycoprotein peptide (MOG- ${ }_{35-55}$ ) offers several advantages as a model of primary synaptic injury. Similar to MS gray matter, the EAE hippocampus has significant microglial activation with minimal lymphocyte infiltration, and undergoes atrophy of pyramidal cell layers and synapse loss accompanied by changes in synaptic transmission and hippocampal-dependent behavioral deficits (Ziehn et al., 2010, 2012b; Kim do et al., 2012). In contrast to MS, inflammatory demyelination and axon injury occur predominantly in the spinal cord and optic nerves in this EAE model with relative sparing of the brain, including preservation of axons projecting from hippocampal pyramidal neurons (Ziehn et al., 2010). Thus, the EAE hippocampus provides the opportunity to study neuronal injury in the setting of local microglial activation and remote lymphocyte-driven neuroinflammation, divorced from demyelination and axotomy.

We investigated relationships between pyramidal neuron synapses and activated microglia in the hippocampus at near-peak and chronic stages of inflammation in $\mathrm{MOG}_{35-55}$-induced EAE. Immunocytochemical and protein data demonstrate injury to excitatory postsynaptic structures associated with phagocytosis of debris by activated microglia and relative preservation of excitatory presynaptic terminals and myelin. In vitro studies of BV2 microglial cells cocultured with hippocampal neurons show that PAF receptor (PAFR) signaling mediates an increase in neuronal vulnerability to excitotoxic injury in the presence of activated BV2 cells, and in vivo treatment with the PAFR antagonist BN52021 prevented excitatory synapse loss in mice with EAE. These results indicate that excitatory synapses are vulnerable to injury in gray matter remote from focal inflammation and independent of demyelination and axotomy, lending support to the concept that synaptic damage is a significant source of neurologic morbidity in MS.

\section{Materials and Methods}

Animals. C57BL/6 mice from a breeding pair or purchased at age 7 weeks (The Jackson Laboratory) were reared to age 8-10 weeks in vivarium housing. Experiments and care were done under approval of the University of Rochester University Committee on Animal Resources according to the Public Health Service Policy on Humane Care and Use of Laboratory Animals.

$E A E$. We immunized mice of either gender with myelin oligodendrocyte glycoprotein peptide, amino acids $35-55$ (MOG $_{35-55}, 100 \mu \mathrm{g}$ per mouse, Mimotopes) emulsified in complete Freund's adjuvant containing heat-inactivated mycobacterium tuberculosis H37RA $(8 \mathrm{mg} / \mathrm{ml}, \mathrm{BD}$ Biosciences), by injecting $25 \mu \mathrm{l}$ emulsion subcutaneously at each of four sites over the shoulder blades and flanks followed by pertussis toxin $(300$ ng i.p., List Biological) on 0 and $2 \mathrm{~d}$ postimmunization (dpi). $\mathrm{MOG}_{35-55}$ was omitted from the complete Freund's adjuvant emulsion for shamimmunized sex-matched littermate controls, which otherwise received identical treatment. Mice were subsequently monitored for signs of clinical disease and scored for motor deficits as follows: 0 , no deficit; 0.5 , partial tail paralysis; 1 , complete tail paralysis; 2 hindlimb weakness; 2.5 , paralysis of one hindlimb; 3, paralysis of both hindlimbs; 3.5 , hindlimb paralysis and forelimb weakness; 4; quadriplegia; 5; moribund. EAE scores are expressed as mean $\pm \mathrm{SE}$.

To induce more uniform disease for treatment experiments with the CNS-penetrant PAFR antagonist BN52021, we immunized 10-week-old male mice with premixed $\mathrm{MOG}_{35-55}$-complete Freund's adjuvant or control emulsion (Hooke Laboratories), $100 \mu \mathrm{l}$ subcutaneously at each of two sites (upper and lower back) followed by pertussis toxin (230 ng i.p., Hooke Laboratories) on days 0 and 1 dpi. Beginning on day 1, we injected $\mathrm{MOG}_{35-55^{-}}$and sham-immunized mice with BN52021 (Selleckchem, dissolved at $4 \mathrm{mg} / \mathrm{ml}$ in 5\% DMSO, $40 \%$ polyethylene glycol 400 , $55 \%$ saline) at a dose of $20 \mathrm{mg} / \mathrm{kg}$ intraperitoneally once daily or equivalent volume of vehicle at the same frequency, for the following treatment groups: Sham-vehicle, Sham-BN52021, EAE vehicle, and EAE-BN52021. To test whether BN52021 could rescue deficits after development of EAE and to avoid confound by potential effects on EAE induction, we included a delayed treatment group: $\mathrm{MOG}_{35-55^{-}}$ immunized vehicle-treated mice were randomized $2 \mathrm{~d}$ after onset of EAE motor deficits (in pairs matched for latency to onset and initial disease severity) to continue treatment with vehicle (group "EAE vehicle") or to begin receiving BN52021 (group "EAE-BN52021 delayed"). Treatment continued until mice were killed $14 \mathrm{~d}$ after onset of EAE motor deficits or the equivalent dpi for sham-immunized mice. We compared EAE scores between treatment groups using the Mann-Whitney $U$ test for nonparametric values.

Immunohistochemistry. At 25 or $55 \mathrm{~d}$ dpi, or $14 \mathrm{~d}$ after EAE onset for BN52021-treated animals and matched controls, mice were anesthetized with ketamine/xylazine (200 and $1 \mathrm{mg} / \mathrm{kg}$, respectively) and perfused via an intracardiac route for $1 \mathrm{~min}$ with PBS containing EDTA $(1.5 \mathrm{mg} / \mathrm{ml})$ followed by $4 \%$ PFA (100 $\mathrm{ml}$ perfused over $30 \mathrm{~min}$ ). Brains were removed, postfixed for $24 \mathrm{~h}$ in $4 \% \mathrm{PFA}$, and stored in PBS at $4^{\circ} \mathrm{C}$. Coronal sections ( $40 \mu \mathrm{m}$ thick) were cut on a vibratome (Leica V1000) and stored in cryoprotectant $(30 \%$ PEG300, 30\% glycerol, $20 \% 0.1 \mathrm{M}$ phosphate buffer, and $20 \% \mathrm{H}_{2} \mathrm{O}$ ) at $-20^{\circ} \mathrm{C}$. Free-floating sections were washed in PBS $(3 \times 30 \mathrm{~min})$ followed by glycine $(100 \mathrm{~mm})$ to reduce autofluorescence, incubated in citrate antigen unmasking solution (Vector H3300) with $0.05 \%$ Tween for $30 \mathrm{~min}$ at $37^{\circ} \mathrm{C}$, and washed again in PBS. We incubated sections for $2 \mathrm{~d}$ at room temperature in 1.5\% BSA (Sigma), 3\% normal goat serum (Vector Laboratories), $0.5 \%$ Triton X-100 (Promega), and $1.8 \% \mathrm{NaCl}$ for blocking and permeabilization, mixed with 
the following primary antibodies: mouse anti-PSD95 (NeuroMab 75028, 1:500), guinea pig anti-VGLUT1 (Synaptic Signaling, 1:2500), rabbit anti-Iba1 (Wako Biochemicals 019-19741, 1:1000), rat anti-myelin basic protein (MBP, EMD Millipore, 1:500), and mouse anti-E06 (Avanti Polar Lipids, 1:500). We washed sections in PBS with $1.8 \% \mathrm{NaCl}(3 \times 30$ $\mathrm{min})$ and then incubated overnight at room temperature with AlexaFluor-conjugated secondary antibodies (Invitrogen, 1:500) in the same blocking/permeabilization mixture as above. After washing in PBS $(3 \times 30 \mathrm{~min})$, we mounted sections on slides with Prolong Gold mounting agent (Invitrogen) and \#1.5 cover glass.

Tissue section imaging and analysis. Slides were coded during image collection and analysis to blind the experimenters to treatment condition. We imaged tissue sections by grid pseudoconfocal microscopy, using an Olympus BX-51 microscope equipped with Quioptic Optigrid hardware for optical sectioning and a Hamamatsu ORCA-ER camera, controlled by Volocity 3DM software (PerkinElmer Life and Analytical Science). Differences in $z$-axis registration of different fluors were corrected by calibration with multicolor fluorescent beads. We imaged the dorsal CA1 hippocampal area, collecting images from 6 sections per animal and using identical light intensity and exposure settings for all animals within each image set. We quantified density of presynaptic and postsynaptic puncta from $60 \times$ image stacks $(z$-step $=0.3 \mu \mathrm{m})$ of PSD95 and VGLUT1 staining in the CA1 stratum radiatum, using a customdesigned automated algorithm in Volocity software to identify puncta based on size and local intensity maxima (identified by both Find Objects and Find Spots algorithms). We quantified contact between microglia and postsynaptic structures in identical $60 \times$ image stacks from sections double-labeled for Iba1 and PSD95 by measuring the volume of PSD95positive objects that contacted or overlapped Iba1-positive objects, expressed as a fraction of total volume of Ibal-positive objects. We quantified microglial morphology by measuring total volumes and surface area-to-volume ratios of Ibal-positive objects identified by intensity-based automated segmentation in $20 \times$ image stacks $(z$-step $=$ $0.5 \mu \mathrm{m})$ from CA1 stratum radiatum. Fluorescence intensities of Ibal and E06 staining were measured within these Iba1-positive objects to quantify microglial content of Iba1 and oxidized phospholipids, respectively. MBP intensities within CA1 were quantified by measuring mean $\mathrm{MBP}$ intensity in manually segmented volumes from $10 \times$ images. For all measurements, region of interest values in images from 6 tissue sections per animal were averaged and mean values for each animal, expressed relative to age- and sex-matched sham-immunized controls, were subsequently compared using two-tailed Student's $t$ tests. Correlations between imaging measurements and nonparametric EAE scores were tested using Spearman's rank correlation. All imaging measurements are expressed as mean $\pm \mathrm{SD}$. Unless otherwise noted, all image stacks are displayed as 2-dimensional extended-focus images collapsed along the $z$-axis.

Western blots. For protein analysis, $\mathrm{MOG}_{35-55^{-}}$and sham-immunized mice were anesthetized as above and perfused briefly ( $45 \mathrm{~s}$ ) with ice-cold PBS at 23 dpi before brains were rapidly removed, hippocampi dissected and frozen on dry ice. Hippocampal protein was extracted by homogenization in lysis buffer (Thermo Fisher Scientific) with protease inhibitors (Sigma), centrifuged at $1200 \times g$ for $10 \mathrm{~min}$ at $4^{\circ} \mathrm{C}$, and removed from the precipitate. We mixed $20 \mu \mathrm{g}$ samples with loading buffer containing SDS, boiled for $5 \mathrm{~min}$, ran samples from each animal on each of three $4 \%-15 \%$ polyacrylamide gels (Bio-Rad) at $100 \mathrm{~V}$, and transferred the protein to nitrocellulose membranes at for $60 \mathrm{~min}$ at $100 \mathrm{~V}$. We blocked membranes overnight at room temperature in $5 \%$ milk in Tris-buffered saline with $0.05 \%$ Tween 20 (TBST) and incubated with primary antibodies at the following dilutions in 5\% milk TBST: antisynaptophysin (Sigma 5768, 1:250); anti-synapsin1 (Cell Signaling 5297); or anti-GluR1 (NeuroMab N355/1, 1:1000) with anti- $\beta$-actin (Santa Cruz Biotechnology 47778, 1:1000). After washing $(3 \times 5 \mathrm{~min}$ in TBST), we incubated with HRP-conjugated secondary antibodies (BioRad, 1:5000 in 5\% milk TBST), washed again, added chemiluminescent substrate (Thermo Fisher Scientific) for $1 \mathrm{~min}$, and exposed on film (Phenix Research Products). For protein loading controls or additional protein quantification, we stripped membranes (Millipore 2504), blocked for $30 \mathrm{~min}$ in $5 \%$ milk TBST, reprobed with anti- $\beta$-actin or
anti-PSD95 (NeuroMab K28/43, 1:1000), and repeated washing, secondary antibody application, and development as above. We scanned films on a transparency scanner (Hewlett Packard) and measured optical density with NIH ImageJ, with relative densities for all proteins normalized to $\beta$-actin from the same gel and group differences evaluated by twotailed Student's $t$ tests. All protein values are expressed as mean \pm SD.

Hippocampal-BV2 cocultures. We cultured dissociated primary hippocampal cells from embryonic (day 18) rat pups as previously described (Bellizzi et al., 2005), plated on glass coverslips (12 mm, 35,000 cells each) coated with poly-D-lysine (Sigma-Aldrich). We used plating medium of Neurobasal (Invitrogen) supplemented with 2\% FBS (Atlas Biologicals), B27 plus antioxidants (Invitrogen), GlutaMax (2 mM, Invitrogen), and L-glutamic acid (50 $\mu \mathrm{M}$, Sigma) for the first 4 DIV and then replaced it stepwise at 4 and $7 \mathrm{~d}$ for serum- and antioxidant-free maintenance medium consisting of Neurobasal supplemented with Glutamax, B27 without antioxidants (Invitrogen) and an additional increase of $53 \mathrm{~mm}$ $\mathrm{NaCl}$ (to match solutions for physiological experiments). Cultures were treated with the mitotic inhibitor FUDR for $24 \mathrm{~h}$ on DIV 6-7 to prevent subsequent glial proliferation. Cultures were maintained for 20-23 DIV to promote maturation of excitatory synapses before coculture experiments. We maintained the BV2 mouse microglia cell line (gift from Dr. Sanjay Maggirwar) in DMEM (Cellgro) with 10\% FBS, GlutaMax (2 $\mathrm{mm}$ ), and penicillin-streptomycin (Invitrogen ) for 12-24 passages before plating overnight in the same media without antibiotics, and stimulating with lipopolysaccharide (LPS, $500 \mathrm{ng} / \mathrm{ml} \times 6 \mathrm{~h}$ ). Stimulated and unstimulated control BV2 cells were then trypsinized, washed in maintenance media, resuspended in Neurobasal maintenance media, added to hippocampal cultures (20,000 cells per culture), and incubated overnight. In some experiments, PAFR antagonist WEB2086 (10 $\mu \mathrm{M}$, Enzo Life Sciences) was added to coculture media at the time of BV2 cell addition and maintained for the duration of the experiment.

Activity-dependent dendritic injury. To visualize dendrite morphology in live neurons, we transfected hippocampal cultures at 19-21 DIV (before addition of BV2 cells) with GFP (in a pMax plasmid vector driven by a CMV promoter, Lonza) using a calcium phosphate transfection kit (Clontech, BD Biosciences) modified as follows: for each culture, we mixed $1 \mu \mathrm{g}$ DNA with $25 \mu \mathrm{l} \mathrm{CaCl}_{2}(0.25 \mathrm{M})$, added this drop-wise to $25 \mu \mathrm{l}$ Hanks balanced salt solution, incubated for $15 \mathrm{~min}$ to allow precipitation of $\mathrm{Ca}^{2+}$-phosphate-DNA particles, and added this suspension to neuronal cultures in Neurobasal maintenance medium along with NMDA receptor antagonist AP5 (10 $\mu \mathrm{M}$, Tocris Bioscience) to increase transfection efficiency. After $6 \mathrm{~h}$ incubation the suspension was washed out and cultures returned to Neurobasal maintenance media. At $18-24 \mathrm{~h}$ after addition of activated or control BV2 cells, we transferred cocultures to a custom-made imaging chamber on an inverted fluorescence microscope (Olympus IX-70) perfused with bath solution (containing, in $\mathrm{mm}$ as follows: $139.5 \mathrm{NaCl}, 2.5 \mathrm{KCl}, 2 \mathrm{CaCl}_{2}, 1 \mathrm{MgCl}_{2}, 24$ glucose, $5 \mathrm{HEPES}, 0.01$ glycine, $\mathrm{pH} 7.3$ ) flowing at $1 \mathrm{ml} / \mathrm{min}$. We imaged individual GFPexpressing neurons before and after application of depolarizing pulses of $90 \mathrm{~mm} \mathrm{KCl}$ via a multichannel drug delivery pipette (ALA Scientific Instruments) positioned to apply drug uniformly over the dendritic arbor. We applied three pulses of $\mathrm{KCl}$ ( $1 \mathrm{~s}$ long and $10 \mathrm{~s}$ apart) alternating with constant perfusion of bath solution, which we have previously shown to trigger short bursts of action potentials and brief depolarization in target neurons in hippocampal cultures (Bellizzi et al., 2005). In some experiments, we included AP5 $(10 \mu \mathrm{M})$, applied beginning $5 \mathrm{~min}$ before stimulation and washed out for $10 \mathrm{~min}$ before repeat stimulation, to test the dependence of NMDA receptors on dendritic beading. For cocultures treated with WEB2086 beginning with BV2 addition, additional WEB2086 $(10 \mu \mathrm{M})$ was included in the bath and $\mathrm{KCl}$ solutions for the duration of the experiment. We imaged neurons at baseline, $10 \mathrm{~s}$ after the end of $\mathrm{KCl}$ application, and every $30 \mathrm{~s}$ for $8-10$ min thereafter, using a shutter to limit fluorescent light exposure, and compared sequential images to detect development of focal dendritic swellings. We considered neurons to have undergone dendritic beading if any of their dendrites developed focal swellings persisting beyond $5 \mathrm{~min}$. We compared frequencies of dendritic beading between experimental conditions by $\chi^{2}$ test. 

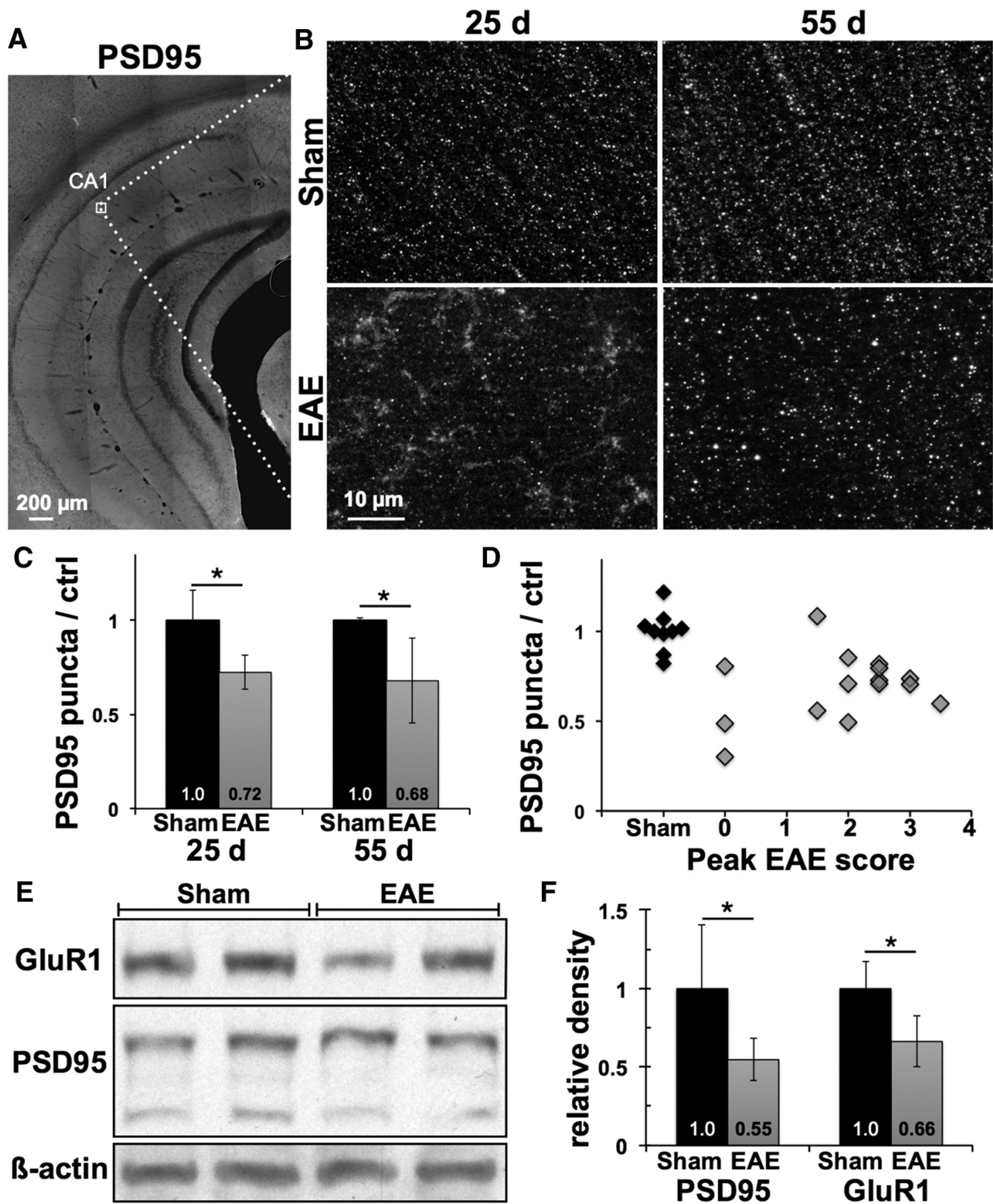

$\mathbf{F}$

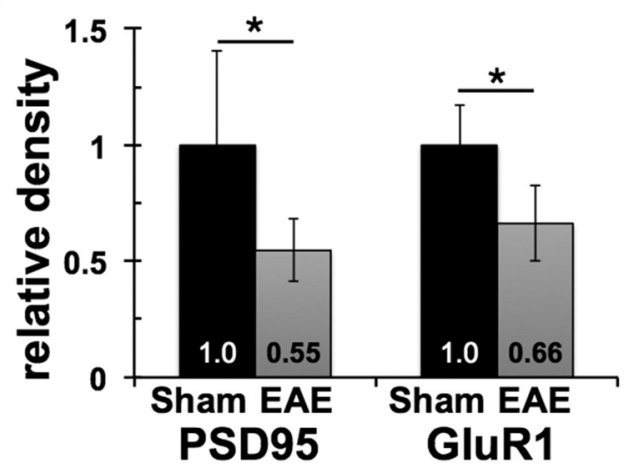

Figure 1. Loss of excitatory postsynaptic structures in EAE hippocampus occurs independent of motor deficits. A, Hippocampal sections immunostained for excitatory postsynaptic marker PSD95 were imaged within the stratum radiatum of area CA1 (box). B, High-power images show that punctate staining for PSD95 was disrupted in EAE mice, with appearance of PSD95-positive material in a nonpunctate pattern at $25 \mathrm{dpi}$ that was cleared by $55 \mathrm{dpi}$. C, Density of PSD95-positive puncta was decreased by $28 \pm 9 \%$ and $32 \pm 22 \%$ in EAE mice at 25 and $55 \mathrm{~d}$ compared with age- and sex-matched sham-immunized controls. $D$, Loss of hippocampal PSD95 puncta at either time point did not correlate with peak severity of motor deficits in EAE mice (Spearman's $\rho=0.16, p=$ 0.56).E, Western blots showed decreases in excitatory postsynaptic proteins PSD95 and GluR1 in hippocampal homogenates from EAEversus sham mice at 23 dpi. All protein bands are from the same gel. $\boldsymbol{F}$, PSD 95 levels normalized to $\beta$-actin were decreased by $45 \pm 13 \%$ in EAE hippocampi compared with sham controls, and GluR1 levels decreased by $34 \pm 16 \%$. ${ }^{*} p<0.05$.

\section{Results}

Microglia engulf injured excitatory postsynaptic structures in EAE hippocampus

To test whether postsynaptic neuronal injury occurs in gray matter areas remote from inflammatory demyelinating lesions in $\mathrm{MOG}_{35-55}$-induced EAE, we measured synaptic density in the stratum radiatum of hippocampal area CA1 in EAE mice at peak and chronic stages of clinical disease. At $25 \mathrm{dpi}$, punctate staining for the excitatory postsynaptic marker PSD95 was disrupted in EAE mice compared with sham-immunized controls, with a $28 \pm$ $9 \%$ reduction in puncta density ( $p=0.01, n=5$ mice per condition), as well as the appearance of PSD95-positive staining in a nonpunctate pattern not seen in any sections from shamimmunized control mice (Fig. $1 B, C$ ). Nonpunctate staining was absent from EAE hippocampi at 55 dpi while puncta density remained reduced, $32 \pm 22 \%$ lower than in controls $(p=0.015$, 

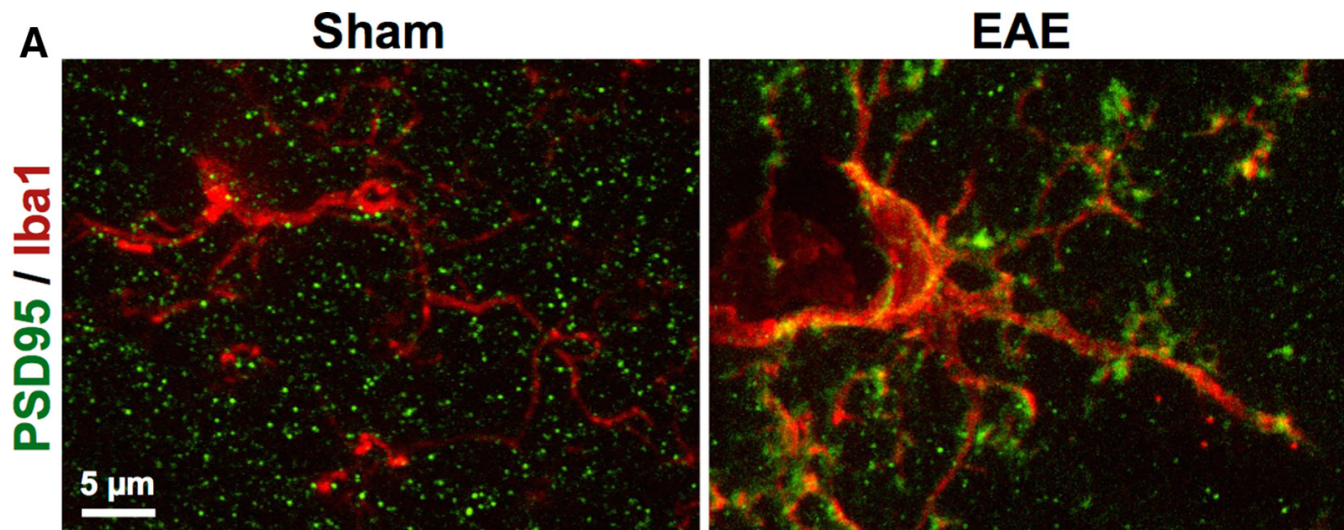

B

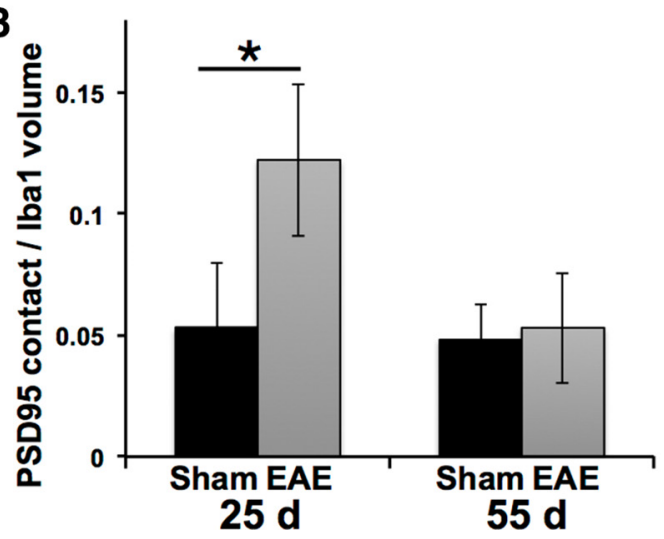

C

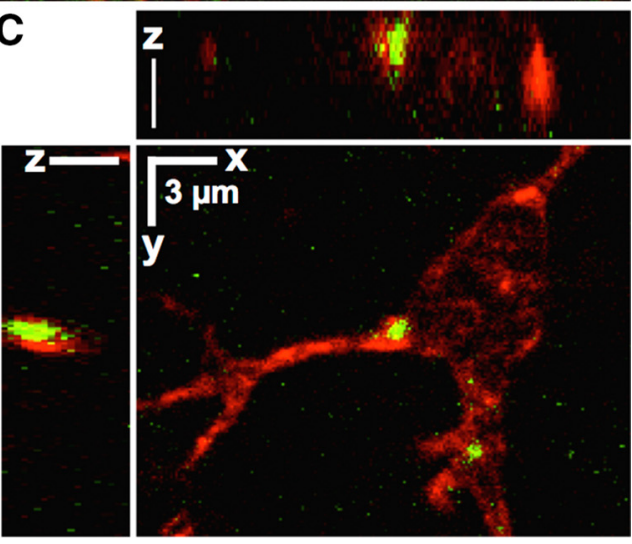

Figure 2. Microglia contact and engulf excitatory postsynaptic structures in EAE hippocampus. A, Loss of PSD95-positive puncta in EAE mice at $25 \mathrm{~d}$ coincided with accumulation of PSD95-positive material along the hypertrophic processes of lba1-positive microglia. $\boldsymbol{B}$, Volume of PSD95-positive structures in contact with microglia was increased $>2$-fold in EAE hippocampi at $25 \mathrm{~d}$ and returned to levels similar to sham-immunized controls by $55 \mathrm{~d}$. ${ }^{*} p=0.004$. C, PSD95-positive inclusions can be seen within Iba1-positive microglia in EAE hippocampus at day 55.

$n=10$ EAE mice and 4 controls). Loss of PSD95-positive puncta in the hippocampus occurred independent of the severity of EAE motor deficits, with no significant correlation between peak EAE score and puncta density in EAE mice across both time points (Spearman's $\rho=0.16, p=0.56$ ) and reduced density evident even in $\mathrm{MOG}_{35-55}$-immunized mice that did not develop any motor deficits (Fig. 1D). Excitatory postsynaptic injury was corroborated by decreased protein levels of PSD95 ( $45 \pm 13 \%$ lower than controls, $p=0.046$ ) and postsynaptic glutamate receptor subunit GluR1 (34 $\pm 17 \%$ lower than controls, $p=0.013$ ) in whole hippocampal homogenates from a separate group of EAE and sham-immunized mice $(n=5$ mice each) at 23 dpi (Fig. $1 E, F$ ).

Costaining with the microglial marker Iba1 revealed a close association between hypertrophic microglial processes and nonpunctate PSD95-positive staining in the EAE hippocampus at 25 dpi, with a $>2$-fold increase in the total volume of PSD95positive material contacted or surrounded by Iba1-positive microglia in EAE versus sham-immunized controls (12 \pm 3.1 vs $5.3 \pm 2.7 \%$ of microglial volume, $p=0.004$; Fig. $2 A, B)$. Вy 55 dpi, when nonpunctate PSD95 staining had cleared, volume of PSD95-microglial contacts returned to control levels, although PSD95-positive inclusions remained apparent in many EAE microglia (Fig. 2C), suggesting microglial clearance of postsynaptic debris.

Excitatory presynaptic structures and myelin remain intact in EAE hippocampus

In contrast to PSD95-positive postsynaptic structures, staining for excitatory presynaptic terminals with VGLUT1 was not dis- rupted in the CA1 stratum radiatum of EAE hippocampi at 25 or 55 dpi (Fig. $3 A, B$ ). Mean density of VGLUT1-positive puncta was similar between $\mathrm{MOG}_{35-55^{-}}$and sham-immunized animals $(0.94 \pm 0.4$ EAE vs $1.01 \pm 0.32$ sham at $25 \mathrm{dpi}, p=0.79$; and $0.99 \pm 0.33$ EAE vs $1.0 \pm 0.06$ sham at $55 \mathrm{dpi}, p=0.96$ ), and punctate staining patterns remained intact at both time points. Likewise, analysis of hippocampal homogenates showed preservation of the presynaptic proteins synaptophysin $(1.07 \pm 0.31$ EAE vs $1.0 \pm 0.23$ sham, $p=0.68, n=5$ mice each) and synapsin-1 $(0.91 \pm 0.17$ EAE vs $1.0 \pm 0.24$ sham, $p=0.52)$ in EAE mice at 23 dpi (Fig. $3 C, D$ ).

We measured intensity of MBP-positive immunostaining to test whether loss of postsynaptic structures corresponded to demyelination either locally within the stratum radiatum, or along axonal projections from CA1 pyramidal neurons in the stratum oriens and alveus (Fig. 4A,B). At 25 dpi, there was no myelin loss in either region in EAE mice compared with sham-immunized controls ( $1.05 \pm 0.08$ EAE vs $1.0 \pm 0.04$ sham, $p=0.26$ in stratum radiatum; $1.21 \pm 0.25$ EAE vs $1.0 \pm 0.05$ sham, $p=0.11$ in the alveus/stratum oriens, $n=6$ EAE mice and 5 controls). By 55 dpi, MBP staining in EAE mice remained statistically similar to controls within both regions and any trends toward reduction were slight $(0.91 \pm 0.08$ EAE vs $1.0 \pm 0.04$ sham, $p=0.05$ in the stratum radiatum; $0.92 \pm 0.08$ EAE vs $1.0 \pm 0.02$ sham, $p=0.08$ in the alveus/stratum oriens).

Microglia are activated and oxidized in EAE hippocampi Iba1-positive microglia within the CA1 stratum radiatum appeared hypertrophic in EAE mice at $25 \mathrm{dpi}$, consistent with an activated phenotype (Fig. 5A, top). This was reflected by in- 
A

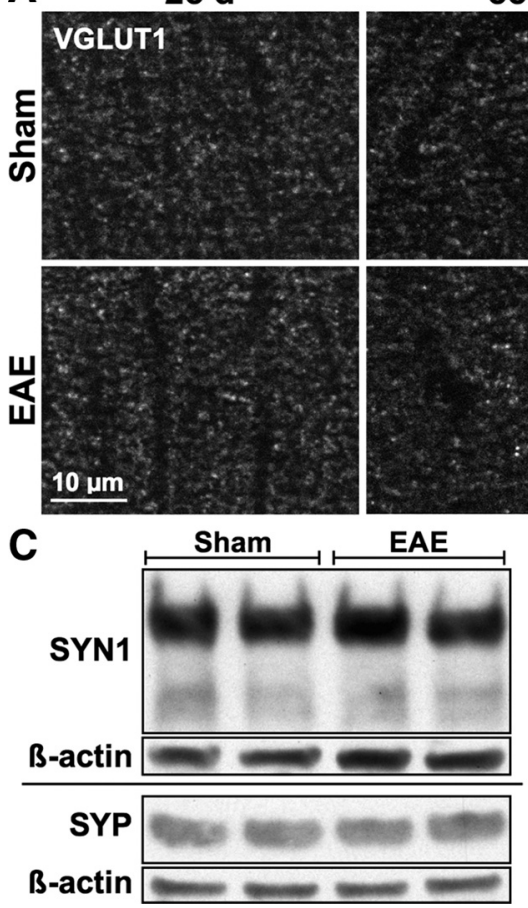

B
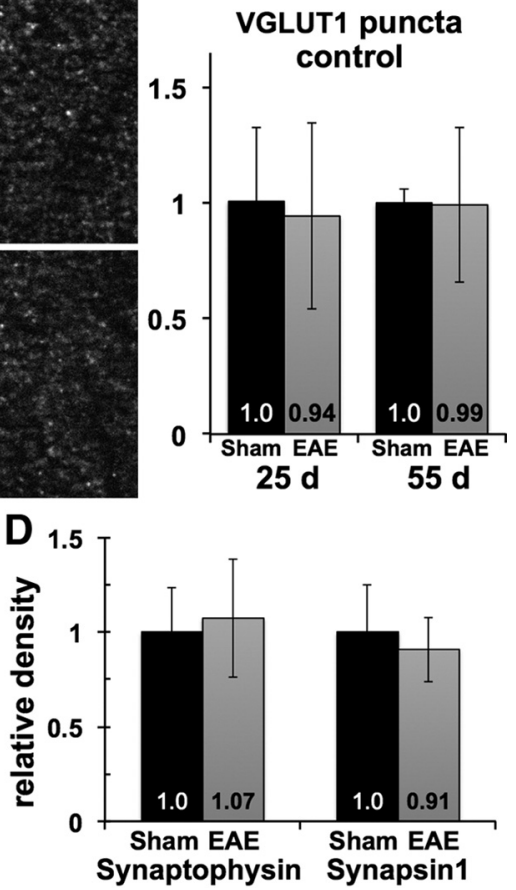

Figure 3. Excitatory axon terminals remain intact in EAE hippocampus. $A, B$, Punctate immunostaining for excitatory presynaptic marker VGLUT1 remained undisturbed within the CA1 stratum radiatum of EAE mice compared with sham-immunized controls, with no change in density or staining pattern at 25 or $55 \mathrm{dpi}$. C, D, Levels of presynaptic proteins synapsin- 1 and synaptophysin were similar in hippocampal homogenates from EAE versus sham-immunized mice at $23 \mathrm{dpi}$. Horizontal divider indicates separate gels.

A
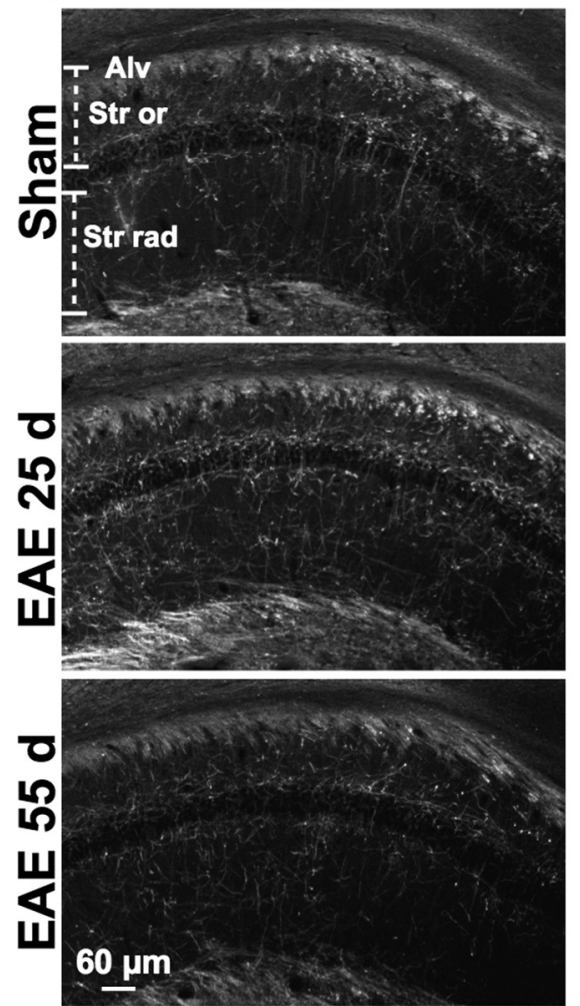

B

\section{Stratum radiatum}
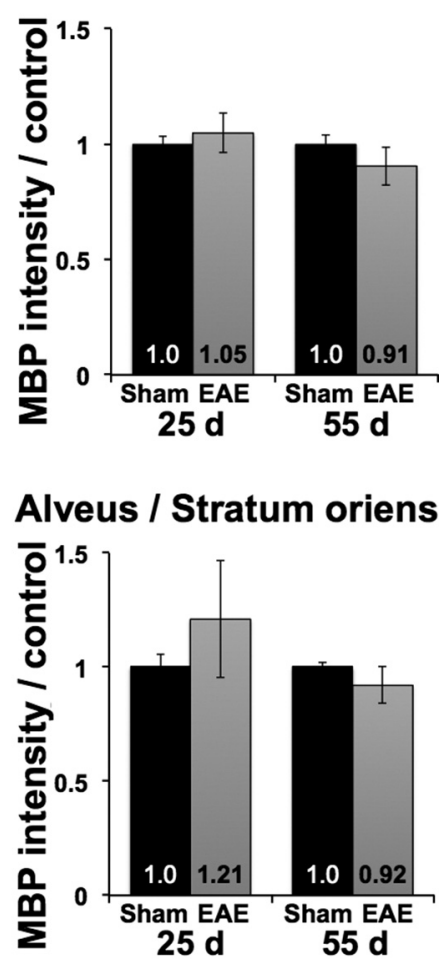

Figure 4. Hippocampal myelin is preserved in EAE. $A$, Immunostaining formyelin basic protein (MBP) was preserved in the CA1 stratum radiatum (Str rad) as well as along pyramidal neuron axons in the stratum oriens (Str or) and alveus (Alv) in EAE mice compared with sham controls ( $25 \mathrm{dpi}$ sham pictured). B, MBP intensity was not decreased in either region at $25 \mathrm{dpi}$, and any attenuation at $55 \mathrm{dpi}$ was mild and not statistically significant.

creased intensity of Ibal staining within microglia at $25 \mathrm{dpi}(1.48 \pm 0.36 \mathrm{EAE}$ vs $1.0 \pm 0.16$ sham, $p=0.02, n=6$ EAE mice and 5 controls) as well as a reduced ratio of surface area to volume $(0.84 \pm 0.09$ EAE vs $1.0 \pm 0.08$ sham, $p=0.01)$ consistent with a more globular morphology in EAE (Fig. 5B). Total microglial volume remained stable $(1.04 \pm 0.09 \mathrm{EAE}$ vs $1.0 \pm$ 0.05 sham at $25 \mathrm{dpi}, p=0.42$; and $1.09 \pm$ 0.13 EAE vs $1.0 \pm 0.002$ sham, $p=0.23$ at 55 dpi), suggesting that these changes were due to activation of tissue-resident microglia rather than recruitment of additional inflammatory cells in EAE. Immunostaining with the E06 monoclonal antibody, which has been used to detect oxidized phospholipids in multiple cell types in the MS brain (Haider et al., 2011), showed an increase in oxidized phospholipids in EAE hippocampi $(1.20 \pm 0.12$ EAE vs $1.0 \pm 0.12$ sham at $25 \mathrm{dpi}, p=$ 0.02 ) that was most prominent in and around Iba1-positive microglia at $25 \mathrm{dpi}$.

Microglia activation waned by $55 \mathrm{dpi}$, with overall measures of Iba1 intensity, surface area-to-volume ratio, and E06 intensity returning to control levels (Fig. $5 B$ ). However, many microglia retained an intermediate morphology with less-ramified processes compared with those of controls as well as less-intense colocalization with E06-positive oxidized phospholipids (Fig. $5 A$ ), suggesting persistence of a chronically reactive state alongside disruption of excitatory postsynaptic structures.

Activated microglia promote activitydependent excitotoxic injury in vitro via a PAFR-dependent mechanism To test whether activated microglia promote excitotoxic postsynaptic neuronal injury, we used an in vitro model of BV2 microglial cells, activated by prior stimulation with LPS or control, added in coculture with primary hippocampal neurons. Following LPS stimulation, BV2 cells developed an activated morphology with hypertrophic, ruffled processes that persisted after trypsinization, washing and replating in LPS-free media overnight (Fig. 6A). In cocultures with LPSactivated BV2 cells, GFP-expressing hippocampal pyramidal neurons maintained a healthy dendrite and spine morphology after 18-24 h but underwent rapid dendritic beading with sustained and enlarging focal swellings following a burst of synaptic activity triggered by bath application of depolarizing $\mathrm{KCl}$. Sustained dendritic beading was reversibly abolished by NMDA receptor antagonist AP5 (10 $\mu \mathrm{M}$; Fig. $6 B, C)$, consistent with 
A
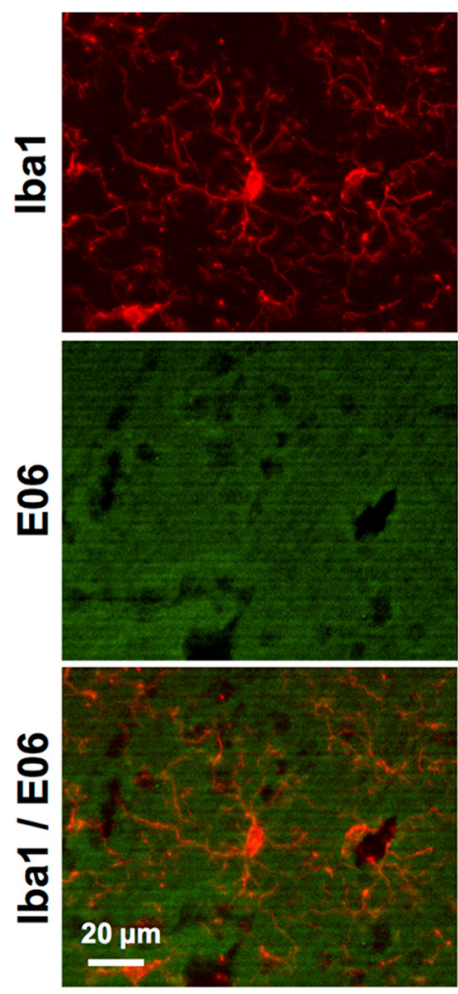

EAE 25 d
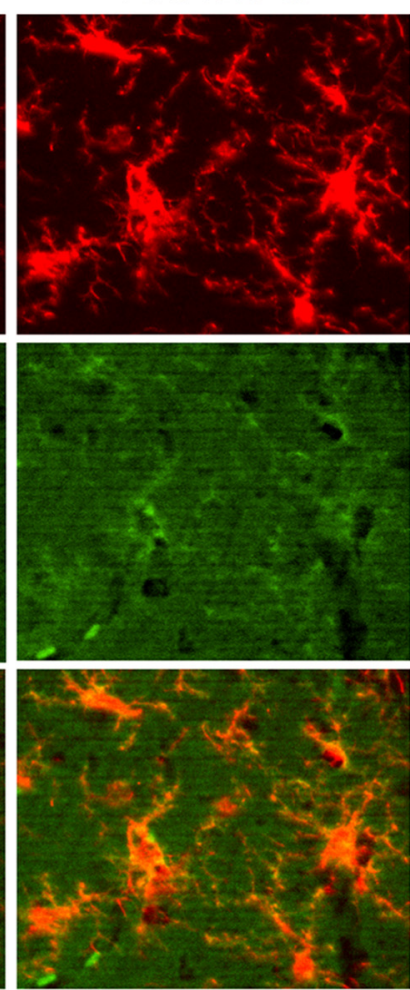

EAE $55 \mathrm{~d}$
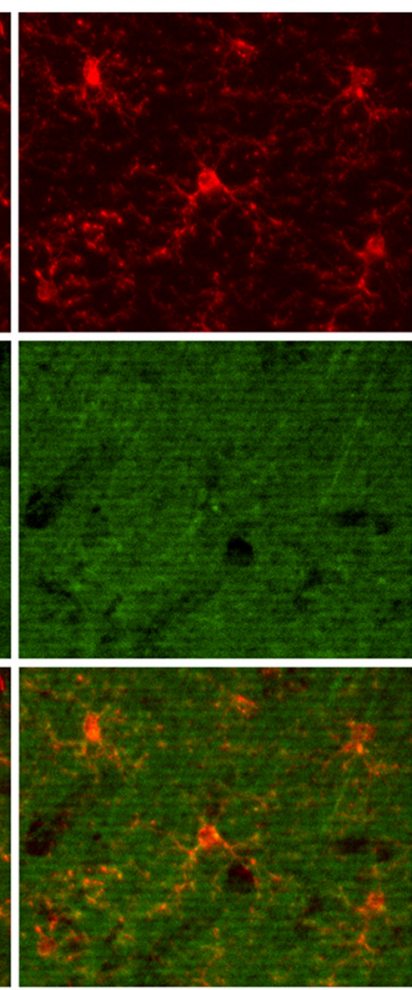

B

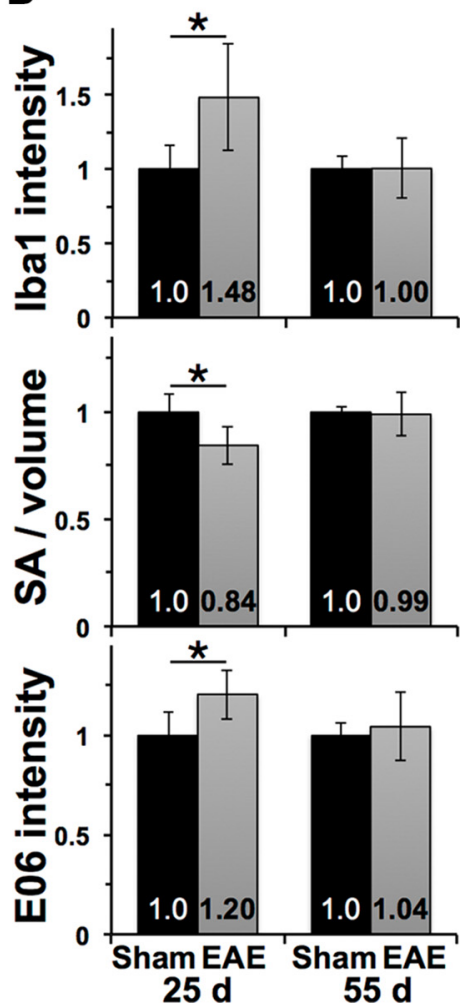

Figure 5. Microglial activation and oxidation in EAE hippocampus. A, Iba1-positive microglia developed a hypertrophic morphology in EAE mice at 25 dpi and an intermediate morphology with shorter and less-ramified processes at $55 \mathrm{dpi} \mathrm{compared} \mathrm{with} \mathrm{those} \mathrm{from} \mathrm{sham-immunized} \mathrm{controls.} \mathrm{Top,} \mathrm{The} 25 \mathrm{dpi}$ sham. E06 immunostaining for oxidized phospholipids was increased within and around microglia in EAE at $25 \mathrm{dpi}$ and was attenuated at $55 \mathrm{dpi}$ with residual staining in some microglia. Bottom, Thresholding applied equally to E06 images. $\boldsymbol{B}$, Segmentation analysis shows increased lba1 intensity, lower surface area-to-volume ratio, and increased E06 intensity within microglia in EAE at 25 dpi. ${ }^{*} p<0.025$ versus sham.

prior studies demonstrating an excitotoxic mechanism for similar activity-dependent postsynaptic injury (Bellizzi et al., 2005). Neuronal vulnerability to KCl-triggered injury was dramatically increased in cocultures with LPS-activated BV2 cells, with $85 \%$ of neurons undergoing beading compared with $14.3 \%$ in cultures with unstimulated BV2 cells ( $p<0.0001, n=34$ neurons).

Because our previous work has demonstrated that PAF is a key mediator of neurotoxicity associated with proinflammatory activated monocytes (Perry et al., 1998) and can determine vulnerability to activity-dependent excitotoxic synaptic injury in hippocampal slices (Bellizzi et al., 2005), we tested whether PAF antagonism would protect neurons in coculture with activated BV2 cells. Addition of PAFR antagonist WEB2086 to LPSactivated BV2 cocultures, beginning at the time of BV2 addition, reduced frequency of beading from $85 \%$ to $21.4 \%$ ( $p=0.0002$ vs vehicle-treated LPS-BV2 cocultures, $n=34$ neurons), similar to that of unstimulated BV2 coculture controls.

\section{PAFR antagonism protects hippocampal synapses in EAE}

We treated $\mathrm{MOG}_{35-55^{-}}$or sham-immunized mice with BN52021, a CNS-penetrant PAFR antagonist, to test for neuroprotection in EAE hippocampus. BN52021 did not prevent onset of EAE. Although mice beginning treatment on day 1 after immunization (EAE-BN52021) had modestly lower EAE clinical scores than mice treated with vehicle (EAE vehicle) or BN52021 delayed until after symptom onset (EAE-BN52021 delayed; Fig. 7A), BN52021 treatment had no effect on microglial activation within the hippocampus: microglia developed nearly identical hypertrophy, increased Ibal intensity ( $1.0 \pm 0.14$ sham-vehicle, $n=7 ; 1.29 \pm$ 0.09 EAE vehicle, $n=7, p=0.0005$ vs sham; $1.27 \pm 0.25$ EAE-
BN52021, $n=5, p=0.03$ vs sham; $1.30 \pm 0.14$ EAE-BN52021 delayed, $n=8, p=0.001$ vs sham) and decreased surface areato-volume ratio $(1.0 \pm 0.13$ sham-vehicle; $0.80 \pm 0.05$ EAE vehicle, $p=0.002$ vs sham; $0.81 \pm 0.1$ EAE-BN52021, $p=0.02$ vs sham; $0.79 \pm 0.5$ EAE-BN52021 delayed, $p=0.0007$ vs sham) regardless of treatment group (Fig. $7 B-D$ ).

In contrast, BN52021 showed marked protective effects against hippocampal synaptic injury in EAE (Fig. 7 E, F). Density of PSD95-positive puncta was decreased by $37 \%$ in EAE vehicle mice $(0.63 \pm 0.25$ EAE vehicle vs $1.0 \pm 0.21$ sham-vehicle, $p=$ 0.01 ) but was preserved at control levels in mice treated from day 1 with BN52021 (0.98 $\pm 0.19, p=0.026$ vs EAE vehicle). BN52021 failed to rescue synapse loss when delayed until after onset of EAE, suggesting that it can prevent but not reverse synaptic injury, and had no effect on PSD95-positive synaptic density in sham-immunized controls. These data are consistent with a direct neuroprotective effect of BN52021 within the hippocampus; although its partial attenuation of EAE clinical scores suggests a modest effect of BN52021 on peripheral immune activation and/or the severity of spinal cord pathology, our data demonstrating the independence of hippocampal synaptic injury from EAE motor deficits (Fig. 1D) argue that such effects are unlikely to be responsible for synaptic protection in the hippocampus. Furthermore, the persistence of microglial activation in EAE-BN52021 hippocampi despite elimination of synaptic injury, together with the above data demonstrating preservation of axons and myelin, suggests that microgliosis occurs independent of local neural injury in the EAE hippocampus and may promote excitatory injury via a PAFR-mediated mechanism. 

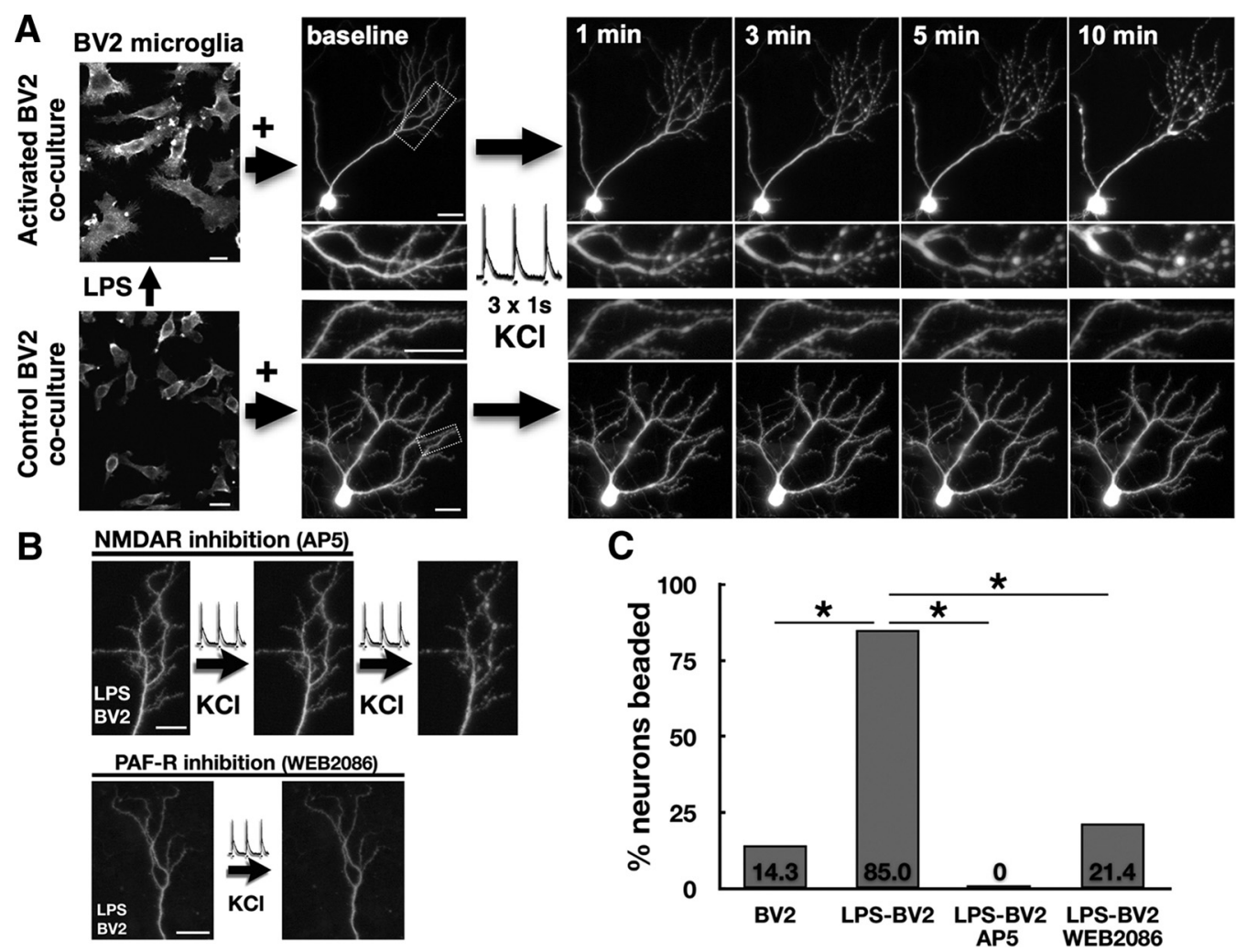

Figure 6. Activated BV2 microglia promote activity-dependent postsynaptic injury. A, GFP-expressing neurons in hippocampal cultures maintained normal dendrite morphology $24 \mathrm{~h}$ after addition of BV2 microglial cells activated by LPS ( $500 \mathrm{ng} / \mathrm{ml}$ for $6 \mathrm{~h}$ ) or unstimulated controls. A burst of synaptic activity triggered by pulses of depolarizing KCI ( $90 \mathrm{~mm}$, three $1 \mathrm{~s} \mathrm{pulses} \mathrm{every} 10 \mathrm{~s}$ ) caused progressive and sustained dendritic beading in neurons cocultured with activated BV2s but not controls (boxed areas enlarged in insets). $\boldsymbol{B}$, KCl-triggered dendritic beading is reversibly blocked by NMDA receptor antagonist AP5 $(10 \mu \mathrm{M})$ and is prevented by addition of PAFR antagonist WEB2086 (10 $\mu \mathrm{M})$ to neurons cocultured with LPS-activated BV2s. C, Rates of KCl-triggered dendritic beading, increased in neurons cocultured with LPS-activated BV2s, were abolished by AP5 and were reduced to control levels by WEB2086. ${ }^{*} p<0.001$. Scale bars, $20 \mu \mathrm{m}$.

\section{Discussion}

Progressive disability in MS is linked to gray matter degeneration that is often widespread and out of proportion to white matter lesion burden. This has been largely attributed to effects of demyelination and axon injury, but these results suggest that degeneration may begin at the afferent end of the neuron as well. In an EAE hippocampal model of gray matter degeneration, we show that neurons undergo excitatory postsynaptic injury independent of demyelination or loss of presynaptic structures. Postsynaptic damage is closely associated with activated microglia, which in vitro studies suggest can promote excitotoxic injury in response to synaptic activity via a mechanism dependent on PAFR signaling. PAFR blockade prevented synaptic injury in EAE hippocampi in vivo without impacting measures of microglial activation, suggesting a neuroprotective effect downstream of CNS inflammation. Together, these findings suggest that excitotoxic postsynaptic injury may be a primary driver of neurodegeneration and synaptic dysfunction in the EAE hippocampus, and might provide an explanation for the MS gray matter degeneration that occurs in the setting of microglial activation, but remote from areas of inflammatory demyelination.

\section{Primary postsynaptic injury in EAE hippocampus}

Loss of both presynaptic and postsynaptic markers has been previously shown to occur alongside hippocampal myelin loss in EAE (Ziehn et al., 2010, 2012a,b). Using an EAE model with a lower dose of $\mathrm{MOG}_{35-55}$ and a less severe clinical phenotype, this study is the first to demonstrate excitatory synaptic injury in the hippocampus that occurs in the absence of local demyelination and independent of clinical motor deficits, and appears to primarily target postsynaptic structures in the initial stages. At $25 \mathrm{~d}$, loss of PSD95-positive puncta coincided with markedly restricted colocalization between microglial processes and PSD95-positive postsynaptic debris, whereas punctate staining for the excitatory presynaptic marker VGLUT1 remained essentially unchanged. Microglia respond vigorously to cell surface markers of neuronal injury, externalized in response to excitotoxicity and other cellular stress (Brown and Neher, 2014). Their selective association with PSD95-positive structures suggests that postsynaptic neuronal dendrites are the primary site of structural injury at excitatory synapses at this stage of disease. This is corroborated by decreases in excitatory postsynaptic proteins PSD95 and GluR1 in hippocampal homogenates at near-peak stages of EAE, with relative preservation of presynaptic proteins synaptophysin and synapsin 1 .

Other synaptic elements are ultimately affected as well in the EAE and MS hippocampus. Staining for synapsin1, expressed at both inhibitory and excitatory axon terminals, has shown substantial loss of presynaptic structures at various stages of EAE and in MS autopsy tissue (Ziehn et al., 2010; 2012b; Dutta et al., 2011), and another study that showed preservation of synapsin1positive structures in EAE nevertheless found decrements in presynaptic function (Ziehn et al., 2012a). As has been previously proposed, this might occur due to additional factors, such as axon injury and the demyelination that is seen in MS hippocampi and to a lesser extent in EAE models with a higher dose of $\mathrm{MOG}_{35-55}$ and a more severe phenotype than this one (Ziehn et al., 2010). However, damage to excitatory postsynaptic structures could 

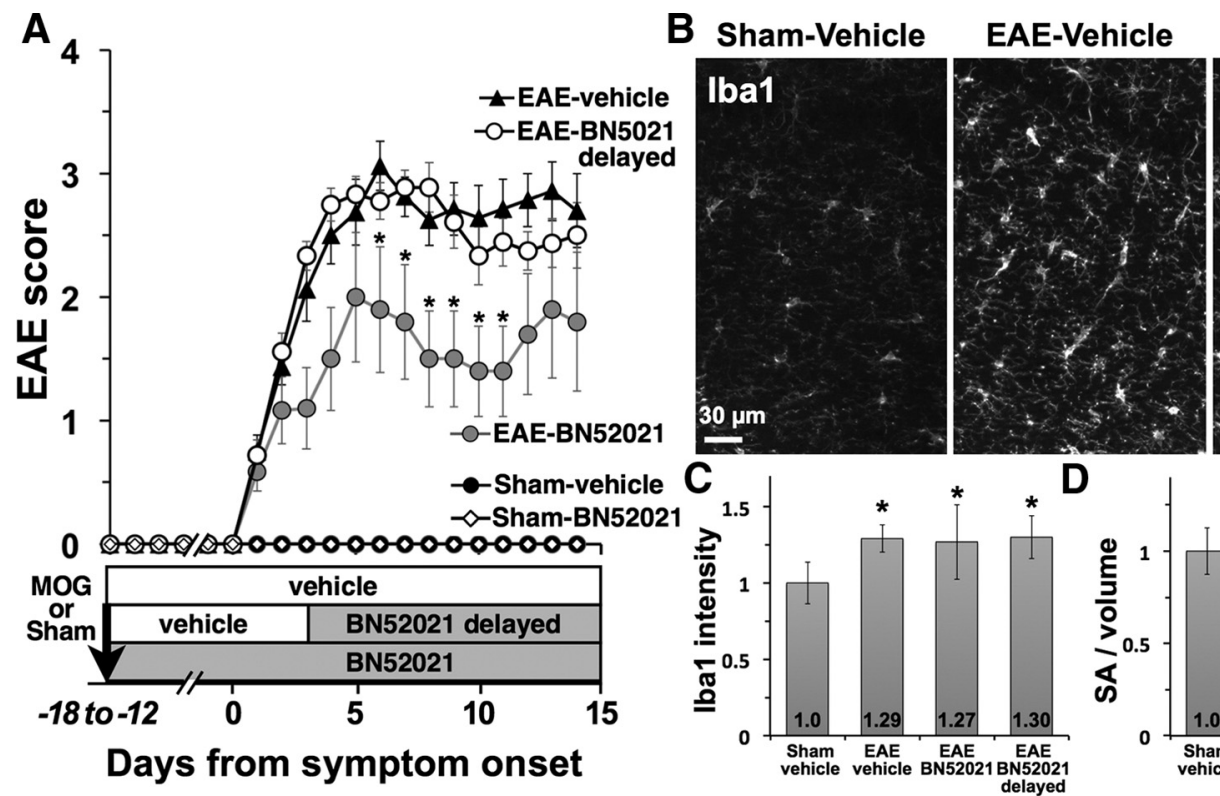

EAE-BN52021
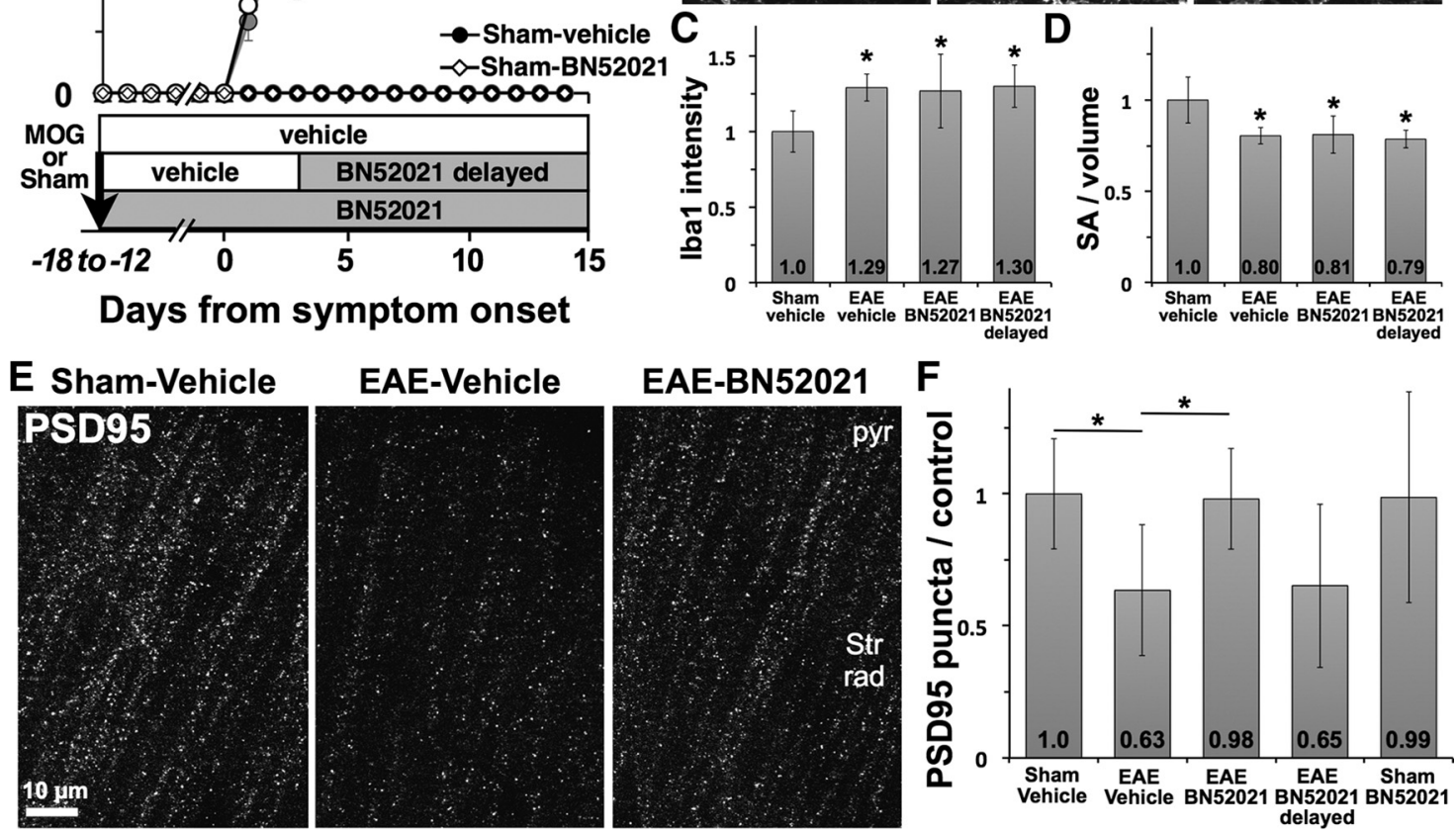

Figure 7. PAFR antagonism protects hippocampal synapses in EAE. A, Treatment with PAFR antagonist BN52021 beginning the day after immunization (EAE-BN52021) did not prevent development of EAE but modestly reduced severity of motor deficits compared with EAE mice treated with vehicle or BN52021 delayed until after onset of motor deficits. ${ }^{*} p<0.05$ versus EAE vehicle. B, BN52021 treatment did not affect activation of Iba1-positive microglia in CA1 hippocampus. pyr, Pyramidal cell layer; Str Rad, stratum radiatum. C, D, Microglial lba1 intensity was increased and surface area-to-volume ratio was decreased in all groups of EAE mice, whether treated with vehicle, BN52021 from day 1, or BN52021 delayed. ${ }^{*} p<0.05$ versus sham-vehicle. $\boldsymbol{E}$, $\boldsymbol{F}$, PSD95-positive synaptic puncta were decreased by 37\% in hippocampi of vehicle-treated EAE mice, and maintained at control levels in EAE mice treated with BN52021. Delayed BN52021 treatment did not protect PSD95-positive synapses in EAE, and BN52021 treatment had no effect on puncta in sham-immunized controls. ${ }^{*} p<0.05$ versus sham-vehicle.

lead to presynaptic changes via disconnection from postsynaptic partners and changes in trans-synaptic signaling (Ziehn et al., 2012a), as well as to compensatory changes in inhibitory networks following disruption of excitatory transmission. Together with prior data showing a predominant loss of PSD95 compared with synapsin1 in the cerebral cortex in EAE (Du et al., 2014), our results raise the possibility that excitatory postsynaptic damage, which we show can occur without loss of myelin or axon inputs, may contribute to broader neurodegeneration in EAE and MS gray matter and may need to be a primary focus of strategies for gray matter neuroprotection.

PAFR and activity-dependent excitotoxicity

Results from our coculture experiments suggest that excitatory postsynaptic damage may occur in the EAE hippocampus via increased vulnerability to glutamate excitotoxicity in a neuroinflammatory setting. We have previously shown that PAF, a phospholipid mediator of synaptic potentiation produced by activated microglia and elevated in the CNS in EAE and MS (Callea et al., 1999; Kihara et al., 2008), can promote NMDA receptor-, calcium-, and caspase-dependent postsynaptic injury in hip- pocampal neurons following synaptic activity that normally triggers physiologic plasticity (Bellizzi et al., 2005). Here we report that activated BV2 microglial cells can promote dendritic beading in cultured hippocampal neurons following a $\mathrm{KCl}$ stimulus that triggers short bursts of neuronal activity and has been shown to induce calcium-dependent synaptic strengthening in healthy cultures (Fitzjohn et al., 2001). In contrast to beading induced by exogenous glutamate receptor agonists that reflects sodium- and chloride-mediated swelling and is rapidly reversible after stimulus washout (Hasbani et al., 1998), KCl-triggered beading in the presence of activated BV2 cells was NMDA receptor-dependent and persisted and/or progressed following the stimulus, consistent with calcium-mediated excitotoxic injury.

Although LPS-stimulated BV2 microglia secrete multiple cytokines with potential to augment glutamate excitotoxicity, including tumor necrosis factor- $\alpha$ and interleukin $-1 \beta$ (Woo et al., 2003), increased dendritic beading in cocultures with activated BV2 cells was eliminated by blockade of PAFRs with WEB2086. Similar to prior studies of neurotoxicity with conditioned media from proinflammatory monocytes (Perry et al., 1998), this suggests a key role for PAFR signaling in mediating neuronal vulner- 
ability within an inflammatory milieu. The ability of BN52021, a PAFR antagonist structurally dissimilar to WEB2086, to prevent excitatory synapse loss in the face of microglial activation in EAE hippocampi further supports this and suggests that excitotoxicity may underlie neuronal injury in vivo as well.

PAFR are expressed by neurons and mediate synaptic potentiation as well as excitotoxicity, likely by augmenting glutamate release (Clark et al., 1992) as well as by coupling postsynaptic NMDA receptor activation to increased nitric oxide production (Xu and Tao, 2004) and subsequent mitochondrial depolarization (Keelan et al., 1999). These events, as well as downstream production of reactive oxygen species and activation of postsynaptic caspases, play roles in both physiologic plasticity and excitotoxic injury (Bellizzi et al., 2005). Our results suggest that, in the presence of activated microglia, PAFR signaling may modulate neuronal excitotoxicity in response to patterns of excitatory activity that would not normally cause injury. Activitydependent excitotoxicity could explain the protective effects of NBQX, an AMPA receptor blocker that decreases excitatory activity, against loss of postsynaptic dendritic spines in the EAE striatum (Centonze et al., 2009) as well as the differential synapse loss found in the MS hippocampus, where activity-dependent plasticity is frequent, versus the motor cortex where it is less so (Dutta et al., 2011).

\section{Microglial activation and synaptic injury}

Neuronal injury correlates with microglial activation in MS gray matter (Magliozzi et al., 2010) and EAE hippocampus (Ziehn et al., 2010), but whether this activation triggers damage or may represent a protective response to it has been unclear (Chen et al., 2014). Prior treatments shown to protect hippocampal neurons in EAE have also attenuated microgliosis and other measures of CNS inflammation (Ziehn et al., 2012a,b; Kim do et al., 2012), leaving this question unresolved. Our data from BN52021 treatment, which prevented synapse loss in EAE hippocampi but had no effect on microglial activation, suggest that neuronal injury occurs downstream of microglial activation and that PAFR signaling may link the two. PAFR are activated not only by PAF, which is produced by proinflammatory microglia in culture (Jaranowska et al., 1995) and in the EAE nervous system (Kihara et al., 2008), but also by numerous species of oxidized phospholipids (Smiley et al., 1991), which our EO6 immunostaining indicates are increased in and around activated microglia in the EAE hippocampus. Thus, there is ample opportunity for microgliosis to trigger PAFR activation, which our data suggest may be a critical step toward development of synaptic damage in EAE hippocampi and perhaps other gray matter areas.

This has important implications for selection of therapeutic targets for gray matter neuroprotection in EAE and possibly MS. While antagonism of glutamate receptors or PAFR has the potential to protect synaptic structures in the short term, these signaling mechanisms are necessary for physiologic plasticity and maintenance of synaptic function. Prior studies suggest that, with these approaches, there may be an insufficient therapeutic window to protect against toxicity while preserving synaptic physiology (Bellizzi et al., 2005), and these data suggest that upstream targets, including modulation of microglial activation, deserve further investigation.

Regardless, these results demonstrate that gray matter postsynaptic structures can be a primary target of injury in autoimmune inflammatory disease, and likely need to be a focus of effective strategies for neuroprotection.

\section{References}

Amato MP, Bartolozzi ML, Zipoli V, Portaccio E, Mortilla M, Guidi L, Siracusa G, Sorbi S, Federico A, De Stefano N (2004) Neocortical volume decrease in relapsing-remitting MS patients with mild cognitive impairment. Neurology 63:89-93. CrossRef Medline

Bellizzi MJ, Lu SM, Masliah E, Gelbard HA (2005) Synaptic activity becomes excitotoxic in neurons exposed to elevated levels of plateletactivating factor. J Clin Invest 115:3185-3192. CrossRef Medline

Brown GC, Neher JJ (2014) Microglial phagocytosis of live neurons. Nat Rev Neurosci 15:209-216. CrossRef Medline

Callea L, Arese M, Orlandini A, Bargnani C, Priori A, Bussolino F (1999) Platelet activating factor is elevated in cerebral spinal fluid and plasma of patients with relapsing-remitting multiple sclerosis. J Neuroimmunol 94: 212-221. CrossRef Medline

Centonze D, Muzio L, Rossi S, Cavasinni F, De Chiara V, Bergami A, Musella A, D'Amelio M, Cavallucci V, Martorana A, Bergamaschi A, Cencioni MT, Diamantini A, Butti E, Comi G, Bernardi G, Cecconi F, Battistini L, Furlan R, Martino G (2009) Inflammation triggers synaptic alteration and degeneration in experimental autoimmune encephalomyelitis. J Neurosci 29:3442-3452. CrossRef Medline

Chen Z, Jalabi W, Hu W, Park HJ, Gale JT, Kidd GJ, Bernatowicz R, Gossman ZC, Chen JT, Dutta R, Trapp BD (2014) Microglial displacement of inhibitory synapses provides neuroprotection in the adult brain. Nat Commun 5:4486. CrossRef Medline

Clark GD, Happel LT, Zorumski CF, Bazan NG (1992) Enhancement of hippocampal excitatory synaptic transmission by platelet-activating factor. Neuron 9:1211-1216. CrossRef Medline

Dehmeshki J, Chard DT, Leary SM, Watt HC, Silver NC, Tofts PS, Thompson AJ, Miller DH (2003) The normal appearing grey matter in primary progressive multiple sclerosis: a magnetisation transfer imaging study. J Neurol 250:67-74. CrossRef Medline

Du S, Itoh N, Askarinam S, Hill H, Arnold AP, Voskuhl RR (2014) XY sex chromosome complement, compared with $\mathrm{XX}$, in the CNS confers greater neurodegeneration during experimental autoimmune encephalomyelitis. Proc Natl Acad Sci U S A 111:2806-2811. CrossRef Medline

Dutta R, Trapp BD (2011) Mechanisms of neuronal dysfunction and degeneration in multiple sclerosis. Prog Neurobiol 93:1-12. CrossRef Medline

Dutta R, Chang A, Doud MK, Kidd GJ, Ribaudo MV, Young EA, Fox RJ, Staugaitis SM, Trapp BD (2011) Demyelination causes synaptic alterations in hippocampi from multiple sclerosis patients. Ann Neurol 69: 445-454. CrossRef Medline

Fisniku LK, Chard DT, Jackson JS, Anderson VM, Altmann DR, Miszkiel KA, Thompson AJ, Miller DH (2008) Gray matter atrophy is related to longterm disability in multiple sclerosis. Ann Neurol 64:247-254. CrossRef Medline

Fitzjohn SM, Pickard L, Duckworth JK, Molnar E, Henley JM, Collingridge GL, Noël J (2001) An electrophysiological characterisation of long-term potentiation in cultured dissociated hippocampal neurones. Neuropharmacology 41:693-699. CrossRef Medline

Haider L, Fischer MT, Frischer JM, Bauer J, Höftberger R, Botond G, Esterbauer H, Binder CJ, Witztum JL, Lassmann H (2011) Oxidative damage in multiple sclerosis lesions. Brain 134:1914-1924. CrossRef Medline

Hasbani MJ, Hyrc KL, Faddis BT, Romano C, Goldberg MP (1998) Distinct roles for sodium, chloride, and calcium in excitotoxic dendritic injury and recovery. Exp Neurol 154:241-258. CrossRef Medline

Jaranowska A, Bussolino F, Sogos V, Arese M, Lauro GM, Gremo F (1995) Platelet-activating factor production by human fetal microglia: effect of lipopolysaccharides and tumor necrosis factor-alpha. Mol Chem Neuropathol 24:95-106. CrossRef Medline

Keelan J, Vergun O, Duchen MR (1999) Excitotoxic mitochondrial depolarisation requires both calcium and nitric oxide in rat hippocampal neurons. J Physiol 520:797-813. CrossRef Medline

Kihara Y, Yanagida K, Masago K, Kita Y, Hishikawa D, Shindou H, Ishii S, Shimizu T (2008) Platelet-activating factor production in the spinal cord of experimental allergic encephalomyelitis mice via the group IVA cytosolic phospholipase A2-lyso-PAFAT axis. J Immunol 181:5008-5014. CrossRef Medline

Kim do Y, Hao J, Liu R, Turner G, Shi FD, Rho JM (2012) Inflammationmediated memory dysfunction and effects of a ketogenic diet in a murine model of multiple sclerosis. PLoS One 7:e35476. CrossRef Medline

Magliozzi R, Howell OW, Reeves C, Roncaroli F, Nicholas R, Serafini B, Aloisi 
F, Reynolds R (2010) A gradient of neuronal loss and meningeal inflammation in multiple sclerosis. Ann Neurol 68:477-493. CrossRef Medline

Perry SW, Hamilton JA, Tjoelker LW, Dbaibo G, Dzenko KA, Epstein LG, Hannun Y, Whittaker JS, Dewhurst S, Gelbard HA (1998) Plateletactivating factor receptor activation: an initiator step in HIV-1 neuropathogenesis. J Biol Chem 273:17660-17664. CrossRef Medline

Rudick RA, Lee JC, Nakamura K, Fisher E (2009) Gray matter atrophy correlates with MS disability progression measured with MSFC but not EDSS. J Neurol Sci 282:106-111. CrossRef Medline

Sbardella E, Petsas N, Tona F, Prosperini L, Raz E, Pace G, Pozzilli C, Pantano P (2013) Assessing the correlation between grey and white matter damage with motor and cognitive impairment in multiple sclerosis patients. PLoS One 8:e63250. CrossRef Medline

Simons M, Misgeld T, Kerschensteiner M (2014) A unified cell biological perspective on axon-myelin injury. J Cell Biol 206:335-345. CrossRef Medline

Smiley PL, Stremler KE, Prescott SM, Zimmerman GA, McIntyre TM (1991) Oxidatively fragmented phosphatidylcholines activate human neutrophils through the receptor for platelet-activating factor. J Biol Chem 266: 11104-11110. Medline

Vercellino M, Merola A, Piacentino C, Votta B, Capello E, Mancardi GL, Mutani R, Giordana MT, Cavalla P (2007) Altered glutamate reuptake in relapsing-remitting and secondary progressive multiple sclerosis cortex: correlation with microglia infiltration, demyelination, and neuronal and synaptic damage. J Neuropathol Exp Neurol 66:732-739. CrossRef Medline

Vrenken H, Geurts JJ, Knol DL, van Dijk LN, Dattola V, Jasperse B, van Schijndel RA, Polman CH, Castelijns JA, Barkhof F, Pouwels PJ (2006) Whole-brain T1 mapping in multiple sclerosis: global changes of normalappearing gray and white matter. Radiology 240:811-820. CrossRef Medline

Woo MS, Jang PG, Park JS, Kim WK, Joh TH, Kim HS (2003) Selective modulation of lipopolysaccharide-stimulated cytokine expression and mitogen-activated protein kinase pathways by dibutyryl-cAMP in BV2 microglial cells. Brain Res Mol Brain Res 113:86-96. CrossRef Medline

Xu Y, Tao YX (2004) Involvement of the NMDA receptor/nitric oxide signal pathway in platelet-activating factor-induced neurotoxicity. Neuroreport 15:263-266. CrossRef Medline

Ziehn MO, Avedisian AA, Tiwari-Woodruff S, Voskuhl RR (2010) Hippocampal CA1 atrophy and synaptic loss during experimental autoimmune encephalomyelitis, EAE. Lab Invest 90:774-786. CrossRef Medline

Ziehn MO, Avedisian AA, Dervin SM, O’Dell TJ, Voskuhl RR (2012a) Estriol preserves synaptic transmission in the hippocampus during autoimmune demyelinating disease. Lab Invest 92:1234-1245. CrossRef Medline

Ziehn MO, Avedisian AA, Dervin SM, Umeda EA, O'Dell TJ, Voskuhl RR (2012b) Therapeutic testosterone administration preserves excitatory synaptic transmission in the hippocampus during autoimmune demyelinating disease. J Neurosci 32:12312-12324. CrossRef Medline 